\title{
MICONIA TEOTEPECENSIS (MELASTOMATACEAE), UNA NUEVA ESPECIE DE LA SIERRA MADRE DEL SUR DE GUERRERO Y OAXACA, MÉXICO
}

\author{
Jesús Ricardo de Santiago Gómez \\ Laboratorio de Plantas Vasculares \\ Facultad de Ciencias \\ Universidad Nacional Autónoma de México \\ Circuito Exterior, Ciudad Universitaria \\ 04510 México, D.F.
}

\section{RESUMEN}

Se describe e ilustra a Miconia teotepecensis de Santiago sp. nov. de la Sierra Madre del Sur en los estados de Guerrero y Oaxaca. Se discute también su ubicación dentro de la sección Amblyarrhena y sus relaciones con otras especies cercanas.

\section{ABSTRACT}

Miconia teotepecensis sp. nov. of the Sierra Madre del Sur in the states of Guerrero and Oaxaca is described and illustrated. Its placement within section Amblyarrhena and its relationships to other species are discussed.

Miconia, el género más grande dentro de la familia Melastomataceae, y uno de los mayores dentro de las angiospermas con alrededor de 1000 especies, se distribuye a lo largo de toda la América tropical desde el norte de Argentina hasta el centro-norte de México. Aunque su máxima diversidad se encuentra en la cuenca del Amazonas y regiones adyacentes en América del Sur, México cuenta con un número relativamente alto de especies (90-100), de las cuales poco más de un tercio son exclusivas del país.

Tradicionalmente el género ha sido dividido en 11 secciones (Cogniaux, 1891), de las que 10 aparecen en México. Dentro de esas secciones, Amblyarrhena -que según Cogniaux (1891) y Wurdack (1973 y 1980) presenta como elemento diagnóstico la posesión de estambres con anteras cortas, rectas, oblongas y con el poro diminuto- es probablemente la que tiene más especies endémicas del país. Entre estas últimas existe un grupo cuyas anteras son fuertemente introrsas y el conectivo se prolonga por debajo de las tecas, características que están ausentes en los demás componentes de la sección, presenta además domacios pilosos en el envés de las hojas y estilos declinados, rasgos sumamente raros y aislados dentro de la sección y del género. Wurdack (1968) hace una primera mención de este grupo cuando describe a $M$. heterothrix Gleason \& Wurdack de Guerrero y Michoacán, citando como especies relacionadas a $M$. tepicana Standley, M. madrensis Standley y M. glabrata Cogniaux, apoyándose en algunos de los caracteres mencionados con anterioridad. Observaciones personales han permitido constatar que, dentro de los límites que establece la extrema dificultad para muestrear amplias zonas montañosas del 
occidente y sur de México, la presencia de miembros de este grupo se limita a las Sierras Madre Occidental y Madre del Sur en sus vertientes del Pacífico y a la Sierra Juárez en Oaxaca. En este trabajo se describe una nueva especie perteneciente al conjunto en cuestión que ha sido colectada en la Sierra Madre del Sur en la región centro-occidental de Guerrero y en la zona de la Mixteca cercana a Juxtlahuaca, en Oaxaca.

Miconia teotepecensis de Santiago, sp. nov.

Miconiae glabratae Cogniaux affinis, a qua differt foliis majoribus, margine denticulatis, basi acutis, obtusis vel subcordatis, supra pilis erectis dispersis, pilis pinoideis basi costae, subtus pilis setulosis in nervis secundariis, tertiariis et interdum alibi; hypanthio campanulato-cylindrico, lobis internis calycis minoribus, triangularibus, erectis, toro inter insertiones staminibus pilis glandularibus minutis, ovario $4 / 5$ infero vel fere infero.

Árbol o arbusto de 1-5 m de alto, densa a esparcidamente pubescente con diminutos pelos estrellado-dendríticos y con diminutos e inconspicuos pelos glandulares adpresos; ramas adultas tetrágonas, obtusas, café-rojizas y lisas a longitudinalmente estriadas, glabrescentes. Hojas ovadas, elípticas o ampliamente elípticas, con el ápice agudo o acuminado, margen ciliolado con los cilíolos de 0.5-0.8(1) $\mathrm{mm}$ de largo y 0.5-1 mm distantes entre sí, serrulado, denticulado o irregularmente dentado, base aguda, redondeada, obtusa o subcordada, ocasionalmente desigual, lámina con una relación largo-ancho de aproximadamente 3 a 2, de (4.7)7-12(16.2) cm de largo y de 3.2-8.8(10.3) cm de ancho, 5-plinervada con las venas primarias laterales basales surgiendo a diferentes alturas de la lámina, membranácea, en fresco con la superficie adaxial ampollosa entre las vénulas y la abaxial densamente reticulada con depresiones entre las vénulas, superficie adaxial con pelos cónicos erectos esparcidos, de $0.25-0.5 \mathrm{~mm}$ de largo y con pelos pinoides cortos en la base de la vena central, abaxialmente las axilas de las venas primarias setulosas hacia la base y esparcida a muy esparcidamente setulosas en las venas secundarias terciarias y ocasionalmente en la superficie; pecíolo de 0.7-5.1(6.8) cm de largo. Inflorescencia paniculada, pedunculada o raramente sésil, de (4)10-20 cm de largo, con pelos pinoides diminutos en los nudos; bractéolas filiformes, de 0.4-0.6 mm de largo; pedicelos de 2.8-4.1 mm de largo. Flores pentámeras o raramente tetrámeras o hexámeras; hipantio blanco o rara vez rojizo en antesis, campanulado, de 1.6-2.8 $\mathrm{mm}$ de largo y de 1.8-2 mm de ancho en el ápice, por dentro glabro, con pelos glandulares diminutos entre los sitios de inserción de los estambres; tubo del cáliz de 0.1-0.2 mm de largo, lóbulos internos triangular-acuminados a ampliamente triangulares, de $0.25-0.3 \mathrm{~mm}$ de largo y de 0.3-0.6 mm de ancho, erectos, dientes externos proyectados escasamente $0.2 \mathrm{~mm}$; pétalos blancos, obovados a obovado-oblongos con el ápice asimétrico, retuso y el margen entero, de 2.2-3.1 $\mathrm{mm}$ de largo y de 1.8-2.4 mm de ancho, glabros; estambres dos veces más numerosos que los pétalos, dimórficos, filamentos complanados, tecas biloculares en su madurez con un poro apical y conectivos abultados dorsalmente, prolongados en la base rodeando el ápice del filamento y bilobulados ventralmente, estambres antipétalos con filamentos de 2.2-2.6 mm de largo, tecas oblongas, rectas o escasamente introrsas, de 1.4$1.8 \mathrm{~mm}$ de largo, poro de $0.16 \mathrm{~mm}$ de diámetro, glabras, conectivos prolongados en la base por 0.18-0.32 mm, glabros, los antisépalos con filamentos de 1.15-1.8 mm de largo, tecas 
De Santiago: Miconia teotepecensis, Nueva Especie de la Sierra Madre del Sur
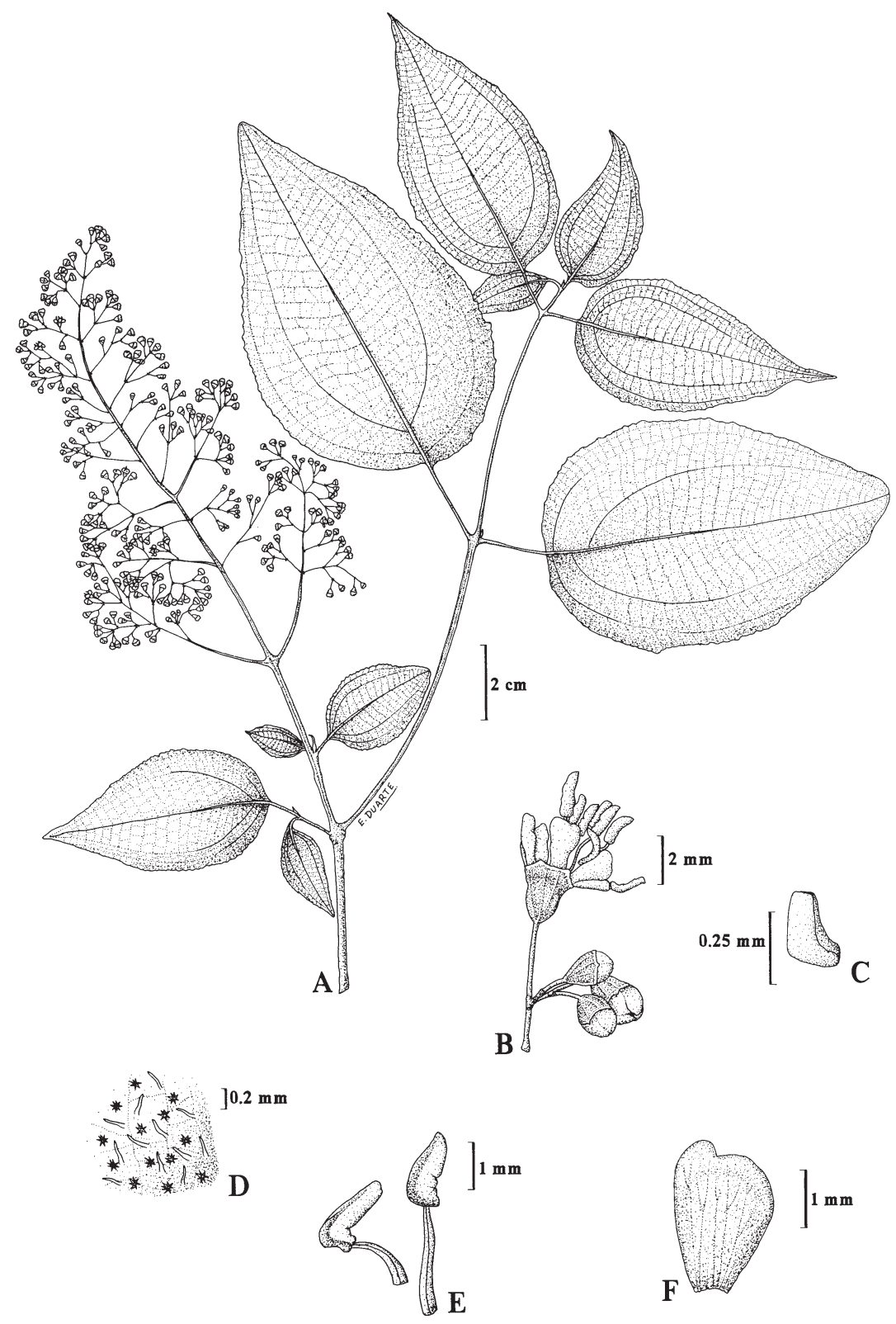

Fig. 1. Miconia teotepecensis de Santiago. A. Rama con inflorescencia; B. Flor en antesis; C. Semilla; D. Detalle de la superficie adaxial, mostrando los tricomas estrellados y simples de la pubescencia; E. Estambres antisépalo (izquierda) y antipétalo (derecha); F. Pétalo. (de Santiago 167). 
oblongas, introrsas cerca de la base adquiriendo hacia el ápice una dirección transversal a los filamentos, de 1.3-1.6 $\mathrm{mm}$ de largo, poros de $0.1 \mathrm{~mm}$ de diámetro, conectivos prolongados por 0.24-0.4 mm, esparcidamente glandular-pubérulos a glabros; ovario (2)3(4) locular, 4/5 a casi totalmente ínfero y con el ápice glabro a esparcidamente glandularpubérulo; estilo cónico, declinado, adquiriendo en el ápice una posición cercana a los poros de los estambres antisépalos, de 2.8-3.2 $\mathrm{mm}$ de largo, y de 0.2 $\mathrm{mm}$ de diámetro en el ápice, glabro o esparcidamente glandular en la parte media; estigma puntiforme, de cerca de $0.2 \mathrm{~mm}$ de diámetro. Frutos abayados, morados o negros, globosos, de 3-4 mm de diámetro. Semillas angostamente piramidales, lisas, de $0.6-0.7(0.9) \mathrm{mm}$ de largo.

Holotipo: México, Guerrero. Municipio de Atoyac de Álvarez, cercanías de El Molote, 17²5'10", 10009'46", restos de bosque mesófilo de montaña, alt. 1750 m s.n.m., julio de 1992. Ricardo de Santiago 167 (Holotipo FCME; isotipos CAS, CHAPA, ENCB, IBUG, IEB, K, MEXU, MO, US).

Paratipos: México, Guerrero. Municipio de Atoyac de Álvarez, steep slope with Pinus and Quercus on the W slope of Cerro Teotepec near Puerto El Gallo, D. E. Breedlove 61956, 61969 and F. Almeda (CAS); steep slope with Quercus below Puerto El Gallo along road to Atoyac, D. E. Breedlove 65124, 65129, 65149 and F. Almeda (CAS); alrededores de El Molote, $R$. de Santiago 11 (CAS, ENCB, FCME, IEB, K, MEXU, MO, US), 13 (FCME), 172 (FCME); 29 km después de El Paraíso, carretera Atoyac-Puerto del Gallo, $R$. de Santiago 62 (ENCB, FCME, MEXU), 63 (FCME, MEXU), 64 (FCME, MEXU); 33 km después de El Paraíso, carretera Atoyac-Puerto del Gallo, R. de Santiago 66 (ENCB, FCME, IEB, MEXU, MO, US); cercanías de El Molote, $R$. de Santiago 163 (ENCB, FCME, IEB, MEXU, US), 164 (FCME, MEXU), 165 (FCME, MEXU), 166 (ENCB, FCME, IEB, MEXU); 3 km después del Puerto de la Piedra Acanalada, carretera Atoyac-Puerto del Gallo, R. de Santiago 176 (FCME, MEXU); 6 km después del Puerto de la Piedra Acanalada, carretera Atoyac-Puerto del Gallo, R. de Santiago 179 (FCME, MEXU); aproximadamente a $1 \mathrm{~km}$ al E de El Molote, R. de Santiago 461 (ENCB, FCME, IEB, MEXU); a 4 km de El Tambor, entre El Tambor y El Paraíso, M. Luna 31 (ENCB, FCME, IEB, MEXU); en Las Golondrinas, a 22 km al NE de El Paraíso, camino a Filo de Caballo, E. Martínez 4236 (ENCB, MEXU); 8 km al NE de El Paraíso, carretera a Puerto del Gallo, P. Tenorio 1364 (ENCB, MEXU); 15.8 mi. by road from Atoyac de Álvarez to Milpillas, W. Wait 2879 (CHAPA). Municipio Petatlán, aproximadamente a $1.5 \mathrm{~km}$ al S de El Venado, $R$. de Santiago 488 (ENCB, FCME, MEXU). Oaxaca. Municipio de Santiago Juxtlahuaca, a $5 \mathrm{~km}$ del poblado El Manzanal, carretera a Infiernillo, J. I. Calzada 20948 (MEXU).

Distribución: Endémica de la Sierra Madre del Sur, en Guerrero en los municipios de Atoyac de Álvarez y Petatlán y en Oaxaca en el municipio de Santiago Juxtlahuaca. A excepción de una sola colecta realizada en el bosque tropical subcaducifolio cercano a El Paraíso, a 1050 m s.n.m. (P. Tenorio 1364), se le encuentra entre los 1500 y los $2000 \mathrm{~m}$ en bosque mesófilo de montaña, bosque de Pinus con elementos de bosque mesófilo y bosque de Pinus-Quercus.

Fenología: Se han colectado ejemplares de Miconia teotepecensis con flor en enero, abril, junio y julio. Mientras que el único ejemplar con frutos maduros existente en herbarios 
mexicanos se colectó en julio, material adicional existente en CAS (Breedlove \& Almeda) extiende el período de fructificación hasta octubre.

Miconia teotepecensis se encuentra situada en un grupo de especies de la sección Amblyarrhena probablemente endémico de México que, como ya se mencionó, presenta como características diferenciales anteras arqueadas introrsamente con el conectivo prolongado en la base y rodeando al filamento en contraste con las anteras rectas y el conectivo no prolongado en la base del resto de las especies de la sección. Miconia glabrata Cogniaux, la especie más parecida a $M$. teotepecensis, comparte con ésta, además de una pubescencia semejante en sus diferentes estructuras, flores casi idénticas y pelos glandulares en la base dorsal del conectivo de los estambres antisépalos. Sin embargo, se distingue de esta última por sus hojas más pequeñas y proporcionalmente más estrechas con la base aguda, menos pubescentes en general y sin pelos simples por el envés a excepción de los domacios menos densos, por sus lóbulos internos del cáliz redondeados y decurvados y por el toro del hipantio sin pelos glandulares en los sitios de inserción de los estambres.

Las restantes especies del grupo antes mencionado, Miconia tepicana Standley, $M$. madrensis Standley, M. heterothrix Gleason \& Wurdack, M. phaeotricha Naudin y otras dos aún no descritas, una de la Sierra de Juárez de Oaxaca y otra de la Sierra Madre del Sur de Jalisco, se distinguen fundamentalmente de $M$. teotepecensis y M. glabrata por los conectivos de los estambres glabros.

\section{AGRADECIMIENTOS}

Agradezco profundamente el apoyo dado por la Maestra en Ciencias Nelly Diego, coordinadora de la Sección de Taxonomía del Laboratorio de Plantas Vasculares de la Facultad de Ciencias de la Universidad Nacional Autónoma de México (UNAM), por el apoyo brindado para la realización de la colecta de material botánico del taxon; a los investigadores del Instituto de Biología de la UNAM, la Dra. Patricia Dávila por sus apuntes críticos al manuscrito y por el apoyo dado para la elaboración del dibujo que acompaña este trabajo, el Dr. Fernando Chiang por su traducción al latín de la diagnosis de la nueva especie y por su crítica del manuscrito y el Dr. Guillermo Ibarra por sus valiosas críticas y participación en la elaboración del manuscrito definitivo; finalmente al Dr. Frank Almeda, de la California Academy of Sciences, por el generoso envío de las fotocopias de los ejemplares de esta especie existentes en el herbario de esa institución.

\section{LITERATURA CITADA}

Cogniaux, A. 1891. Melastomataceae In: de Candolle, A. \& C. Monographiae Phanerogamarum 7: 1-1256. Wurdack, J. J. 1968. Certamen Melastomataceis XII. Phytologia 16: 168-183.

Wurdack, J. J. 1973. Melastomataceae. In: Lasser, T. (ed.) Flora de Venezuela 8: 1-819.

Wurdack, J. J. 1980. Melastomataceae In: Harling, G. y B. Sparre (eds.) Flora of Ecuador 3: 1-406. 